\title{
CORROSION COMPARISON OF GALVANIZED STEEL AND ALUMINUM IN AQUEOUS ENVIRONMENTS
}

\author{
M. Merajul Haque, S. Alam Limon, Md. Moniruzzaman* and \\ Md. Mohar Ali Bepari \\ Department of Materials and Metallurgical Engineering \\ Bangladesh University of Engineering and Technology, Dhaka-1000, Bangladesh \\ *E-mail: mmoniruzzaman@mme.buet.ac.bd \\ Phone: +88029665650/7237; Fax: +88029665618
}

\begin{abstract}
A corrosion test of galvanized steel and aluminum was carried out in three different aqueous environments, $5 \% \mathrm{NaCl}$ solution, sea water and rain water, using the immersion test technique. Corrosion rate was measured in $\mathrm{mdd}\left(\mathrm{mg} / \mathrm{dm}^{2} / \mathrm{day}\right)$ units. Aluminum was considered as a possible alternative to galvanized steel. The corrosion characteristics of the corroded samples were investigated by XRD, XRF and SEM analysis. Although various results were obtained all through this study, aluminum was seen as more corrosion resistant than galvanized steel in the conditions tested in all three aqueous environments. Galvanized steel might be more corrosion resistant than aluminum in long term exposure in rain water. Without taking into account cost comparisons, aluminum can be used as a substitute for galvanized steel in industrial structures (roofing sheets) and water distribution systems.
\end{abstract}

Key words: Corrosion rate (mdd), galvanized steel, aluminum, aqueous environment.

\section{INTRODUCTION}

Metals are very important engineering materials, but the most serious drawback to their mechanical and electrical properties is corrosion. This has a huge economic and environmental impact on virtually all facets of the world's infrastructure, from highways, bridges and buildings, to oil and gas, chemical processing and water and wastewater systems. In addition to causing severe damage and threatening public safely, corrosion disrupts regular operations and requires the extensive repair and replacement of failed assets. Corrosion can only be reduced, however, it cannot be prevented because thermodynamically it is a spontaneous phenomenon. Depending on environment, the corrosion of a particular material can be fast or slow. Sensitized 18-8 stainless steel, for example, is severely attacked in hours by polythionic acid (Syed, 2006). Although the famous iron Delhi Pillar in India was made almost 2000 years ago, and is almost as good as new, it should be noted that it has been exposed to mostly arid conditions (Fontana, 1987). Attempting to reduce corrosion is vital for better industrial production, public safety, avoiding health hazards etc.

Galvanized steel is used in aqueous environments in many indoor and outdoor applications where rust resistance is needed. It is used in applications such as underground pipelines, under sea water, frames to build houses, and many household appliances, automotive body parts, telecommunication industry, power transmission lines, thermal power plant etc. (Lin, Lu, \& Kong, 2008; Sherif, Almajid, Bairamov, \& 
Al-Zahrani, 2012). The protection obtained by zinc ( $\mathrm{Zn}$ ) coating is due to the barrier and galvanic double protective effect (Bajat, Stanković, Jokić, \& Stevanović, 2010; Kartsonakis, Balaskas, Koumoulos, Charitidis, \& Kordas, 2012). Atmospheric corrosion of galvanized steel structures begins through an electrochemical process when the $\mathrm{Zn}$ surface becomes wet with rain, mist, or dew (Nriagu, 1978). The American Galvanizers Association (AGA) conducted tests of the corrosion of galvanized steel in water collected from marine environments all over the USA and found that soft water, tropical sea water, and high oxygen content causes higher corrosion in zinc coating of galvanized steel (American Galvanizers Association).

Aluminum ( $\mathrm{Al})$ is one of the most abundant elements in nature. Its low density, high elastic modulus, thermal and electrical conductivity, corrosion resistance and its capacity to form alloys with many elements makes it one of the most useful materials in construction (Hatch, 1984). Al is used in buildings for a wide spectrum of applications, including plumbing products and replacement windows. The corrosion of $\mathrm{Al}$ has mainly been investigated through field studies (Graedel, 1989). Few laboratory investigations in controlled environments have been published. In one study, it was found that $\mathrm{Al}$ has very low resistance to a corrosive environment $(3 \% \mathrm{NaCl})$ in a static regime, and corrosion processes take place on the Al surface (Hagioglu, Gheorghies, Cantaragiu, \& Moisa, 2010). In another study, the effect of rain on Al alloy and galvanized steel roofing sheets, as well as their relative corrosion resistance, was studied (Abdulkarim, Abdullahi, \& Salam, 2009). The corrosion behavior of pure Al after different immersion intervals in $3.5 \% \mathrm{NaCl}$ solutions was also studied, and it appeared that the corrosion rate of $\mathrm{Al}$ decreased with increasing immersion time due to the growing thickness of the corrosion product (Sherif, Almajid, Latif, \& Junaedi, 2011)

In Bangladesh, roofing systems in most houses in rural areas and some houses in urban areas involve galvanized steel sheets. There is little use of $\mathrm{Al}$ as roofing sheets, but the application of $\mathrm{Al}$ as window frames has recently been increasing. Similarity in applications both for galvanized steel and Al put them in similar environments like saline water, humid atmosphere, rain, weather and so on. Corrosion is the major, and a common challenge to these materials. Although much study has been independently conducted on the corrosion of galvanized steel and Al in various environments, corrosion study of these two materials in common environments are rare. This work makes a comparative study of corrosion behavior of galvanized steel and $\mathrm{Al}$ in three aqueous environments, $5 \% \mathrm{NaCl}$ solution, sea water and rain water. Aqueous environments are chosen as the corroding media because in real case scenarios the substrates come in contact with liquid and gases such as chemical processing plants, plumbing applications, oil rigs, offshore petroleum pipelines, household appliances, roofing sheets, machine parts, marine structures etc.

\section{EXPERIMENTAL DETAILS}

Galvanized steel sheets and $\mathrm{Al}$ sheets of $4.5 \times 2.0 \mathrm{~cm}$ in size were taken as substrates. All substrates were cut from the main sheet by a hand shear cutting machine. The thickness of both substrates was $0.5 \mathrm{~mm}$. The area $\left(\mathrm{A}\right.$ in $\left.\mathrm{dm}^{2}\right)$ of all the substrates was measured using slide calipers. A schematic of the sample geometry is shown in Figure 1(a). All the substrates were cleaned with detergent, washed with acetone and dried. The initial weight ( $\mathrm{w}_{\mathrm{i}}$ in $\mathrm{mg}$ ) of all the substrates was measured using an electronic weighing balance. All parameters were measured at ambient temperature. A $5 \% \mathrm{NaCl}$ solution was prepared using deionized water and reagent grade $\mathrm{NaCl}$ salt; sea 
water was collected from the Bay of Bengal in the Chittagong area; and rain water was collected during rain in Dhaka city. All substrates were then immersed in liquid environments $(5 \% \mathrm{NaCl}$ solution, sea water and rain water). For each environment, five samples were dipped in beakers containing the liquid and kept there for $\mathrm{T}$ days $(\mathrm{T}=1$, 2, 3, 4 and 5 respectively). The experimental set up for corrosion test by immersion is shown in Figure 1(b). All the substrates were then cleaned again with detergent, washed with acetone and dried. Final weights $\left(\mathrm{w}_{\mathrm{f}}\right.$ in $\mathrm{mg}$ ) were measured for all substrates. A flow chart of the experimental procedure for the corrosion test is shown in Figure 2.

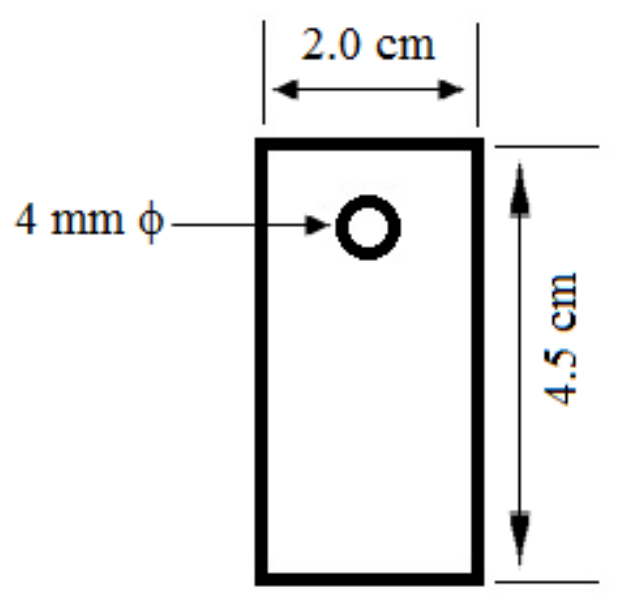

(a)

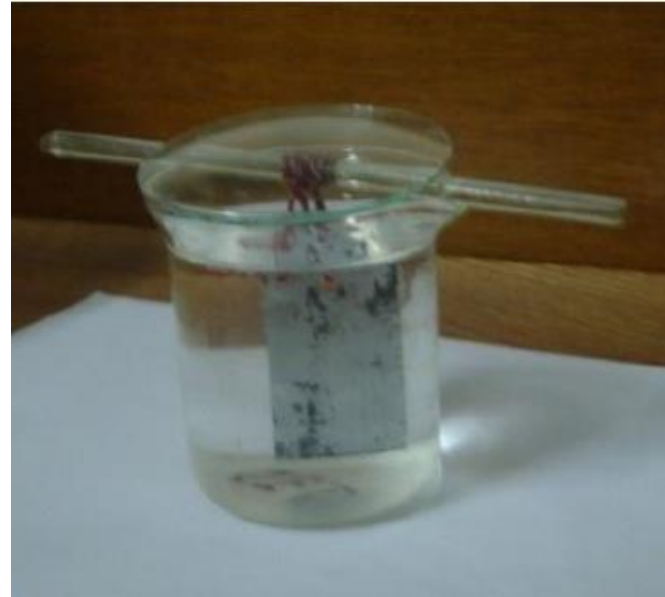

(b)

Figure 1. (a) Schematic geometry of sample and (b) experimental set up of corrosion test by immersion technique.

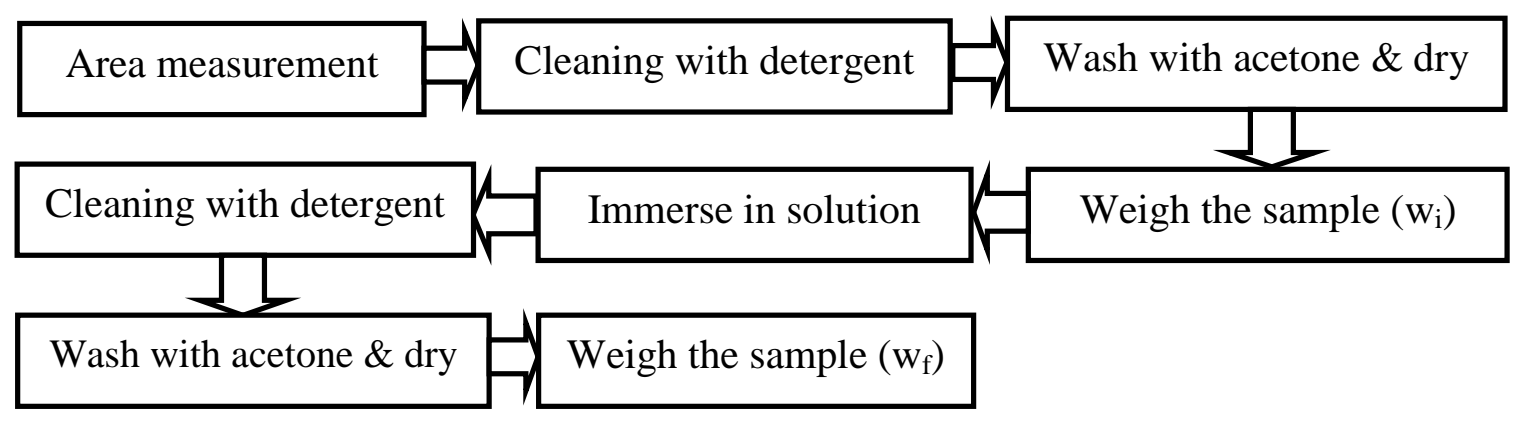

Figure 2. Flow chart of the experimental procedure for corrosion test by immersion.

Corrosion rate in mdd $\left(\mathrm{mg} / \mathrm{dm}^{2} / \mathrm{day}\right)$ unit was measured by using the following formula:

$$
\begin{aligned}
& \text { Corrosion rate }=\frac{W i-W f}{T \times A} \\
& \begin{aligned}
\text { Where, } \mathrm{W}_{\mathrm{i}} & =\text { initial weight of sample in } \mathrm{mg} \\
\mathrm{W}_{\mathrm{f}} & =\text { final weight of sample in } \mathrm{mg} \\
\mathrm{T} & =\text { immersion time in day } \\
\mathrm{A} & =\text { Area of sample in } \mathrm{dm}^{2}
\end{aligned}
\end{aligned}
$$

Corroded surface characteristics were investigated using XRD (X-ray diffractometer), and XRF (x-ray fluorescence). Scanning electron microscopy (SEM) was then 
employed to inspect the surface morphology of the bare substrates and corroded samples.

\section{RESULTS AND DISCUSSION}

\section{Corrosion in Aqueous Environments}

The change in corrosion rate with exposure time for galvanized steel and $\mathrm{Al}$ in various environments is shown in Figure 3. A varied corrosion rate with exposure time both for galvanized steel and Al was observed in various environments. For example, the corrosion rate decreases and increases with an increase of exposure time in $5 \% \mathrm{NaCl}$ solution and sea water respectively for both the substrates. A decreasing trend in the corrosion rate was observed for galvanized steel in rain water which is in contrast to $\mathrm{Al}$ which showed an increasing corrosion rate with exposure time. Within these diverse patterns, the only replicable result was that the corrosion rate for galvanized steel is higher than that of $\mathrm{Al}$ for every test condition. The diverse corrosion behavior in various environments is discussed separately in the following paragraphs.
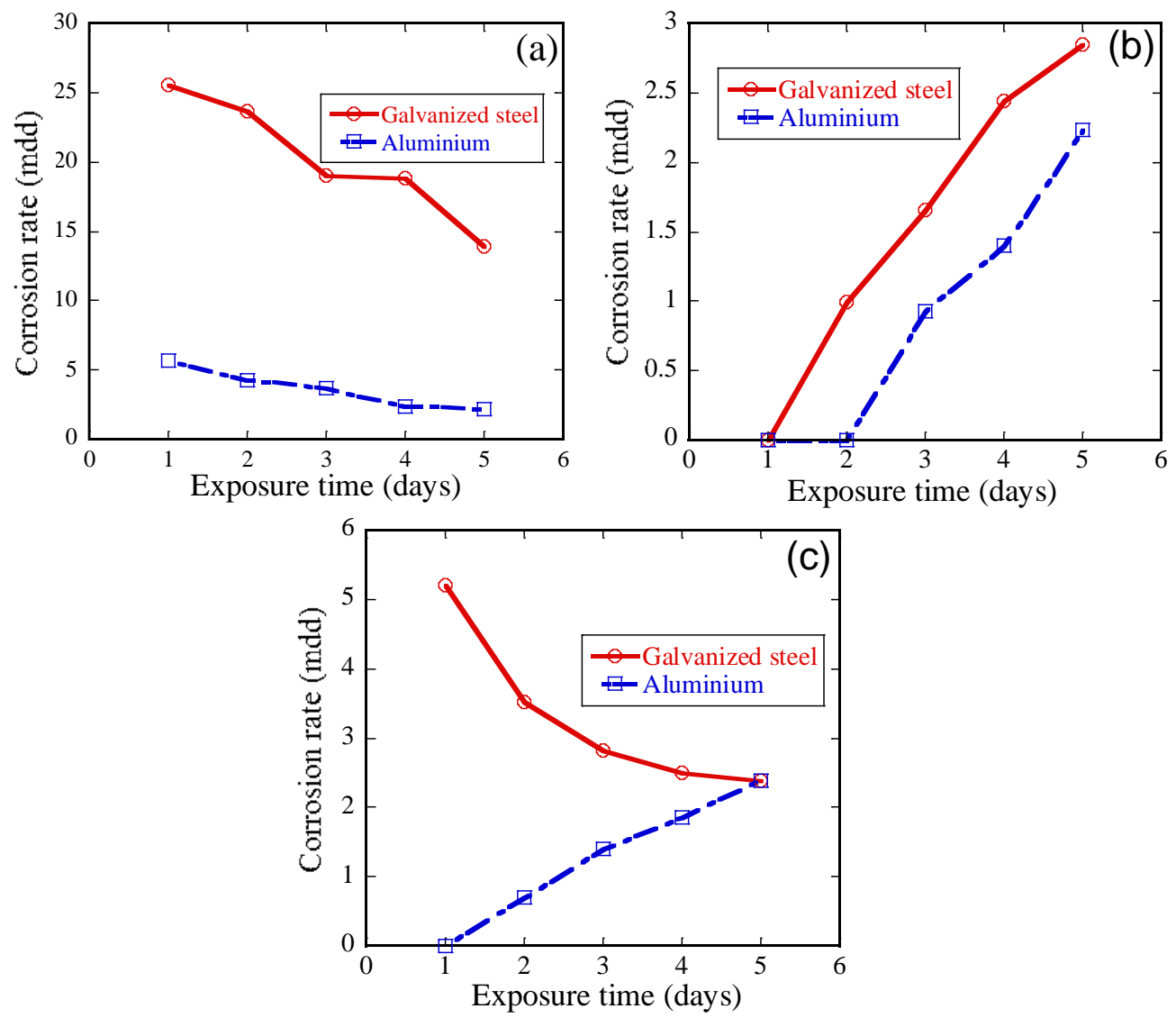

Figure 3. Corrosion rate as a function of the exposure time of galvanized steel and $\mathrm{Al}$

under immersion test in (a) $5 \% \mathrm{NaCl}$ solution, (b) sea water and (c) rain water. (a) Corrosive environment: $5 \% \mathrm{NaCl}$ solution

Both galvanized steel and $\mathrm{Al}$ immersed in $5 \% \mathrm{NaCl}$ solution showed decreasing corrosion rates with increasing exposure time (Figure 3(a)). The value of corrosion rates in mdd for the $\mathrm{Al}$ sample in $5 \% \mathrm{NaCl}$ environment was much lower than for galvanized 
steel. Chlorides are severely corrosive to Zn (American Galvanizers Association), so initially the corrosion rate was high. As most of the $\mathrm{Zn}$ corrodes early, decreasing the chloride concentration in an $\mathrm{NaCl}$ environment with time, corrosion rate decreases with increasing exposure time. Surface analyses of corroded samples by XRF test are shown in Table 1. A galvanized steel sample surface after corrosion in $5 \% \mathrm{NaCl}$ solution contains $47.14 \% \mathrm{Zn}$ and $32.25 \% \mathrm{Fe}$ which indicates major corrosion of the sample. The appearance of this corroded sample is shown in Figure 4. A small fraction of the entire sample surface is seen covered by $\mathrm{Zn}$ coating. The non-adherent corrosion products found in the beaker bottom are $\mathrm{ZnCl}_{2}$ (white crystalline powder or granule). In the XRD pattern, $\mathrm{Zn}$ and chloride peaks are found (Figure 5(a)). Moderate Al corrosion is supposed to be occurred in 5\% $\mathrm{NaCl}$ solution exposing $62 \% \mathrm{Al}$ and $36.71 \% \mathrm{O}_{2}$ as seen in the XRF test. Dissolved $\mathrm{O}_{2}$ and $\mathrm{CO}_{2}$ in distilled water are believed to form protective a film of aluminum oxide to resist further corrosion (Sherif et al., 2011) resulting in much less corrosion of $\mathrm{Al}$ in $5 \% \mathrm{NaCl}$ solution compared to galvanized steel.

\section{b) Corrosive environment: sea water}

Sea water is high in salt content in the form of various chlorides and often the presence of sulfide is detrimental (Jayaraman, 1951). It is a good electrolyte and corrosion is affected by oxygen content, temperature and biological organism (Al-Fozan \& Malik, 2005). It also contains carbonates which form a protective film on a $\mathrm{Zn}$ (American Galvanizers Association) as well as on an Al surface (Wan Nik, Sulaiman, Fadhli, \& Rosliza, 2010). The corrosion rate in sea water is thus much less than in $5 \% \mathrm{NaCl}$ solution for both the samples. The corrosion rate gradually increases with increasing exposure time (Figure 3(b)). Although the corrosion curve in sea water shows an increasing trend, the absolute value in mdd is much lower than in $5 \% \mathrm{NaCl}$ solution as seen through the $\mathrm{Y}$-axis scale. The presence of $\mathrm{Ca}$ and $\mathrm{Mg}$ ions also inhibit corrosion in sea water because they form a protective film of carbonates (American Galvanizers Association).

Table 1. XRF data of samples after corrosion.

\begin{tabular}{|c|c|c|c|c|}
\hline Sample & $\begin{array}{c}\text { Corrosion } \\
\text { environment }\end{array}$ & Elements & Mass $(\%)$ & Remarks \\
\hline \multirow{6}{*}{$\begin{array}{l}\text { Galvanized } \\
\text { steel }\end{array}$} & \multirow{2}{*}{$5 \% \mathrm{NaCl}$ solution } & $\mathrm{Zn}$ & 47.14 & \multirow{2}{*}{ Much Zn corrosion } \\
\hline & & $\mathrm{Fe}$ & 32.25 & \\
\hline & \multirow{2}{*}{ Sea water } & $\mathrm{Zn}$ & 82.43 & \multirow{2}{*}{ Less $\mathrm{Zn}$ corrosion } \\
\hline & & $\mathrm{Fe}$ & 14.13 & \\
\hline & \multirow{2}{*}{ Rain water } & $\mathrm{Zn}$ & 77.01 & \multirow{2}{*}{ Moderate $\mathrm{Zn}$ corrosion } \\
\hline & & $\mathrm{Fe}$ & 12.33 & \\
\hline \multirow{6}{*}{$\mathrm{Al}$} & \multirow{2}{*}{$5 \% \mathrm{NaCl}$ solution } & $\mathrm{Al}$ & 61.99 & \multirow{2}{*}{ Moderate $\mathrm{Al}$ corrosion } \\
\hline & & $\mathrm{O}$ & 36.71 & \\
\hline & \multirow{2}{*}{ Sea water } & $\mathrm{Al}$ & 85.23 & \multirow{2}{*}{ Less $\mathrm{Al}$ corrosion } \\
\hline & & $\mathrm{O}$ & 13.58 & \\
\hline & \multirow{2}{*}{ Rain water } & $\mathrm{Al}$ & 98.8 & \multirow{2}{*}{ Negligible Al corrosion } \\
\hline & & $\mathrm{O}$ & Nil & \\
\hline
\end{tabular}

The presence of $82.43 \% \mathrm{Zn}$ in the XRF test (Table 1) on the corroded galvanized steel sheet in sea water ensures a lesser amount of $\mathrm{Zn}$ surface corrosion than in the $5 \%$ 
$\mathrm{NaCl}$ solution. This is further supported by only $14.13 \%$ Fe exposure of galvanized steel in the sea water corrosion test. An almost linear increase of Al corrosion rate is observed in sea water (Figure 3(b)). XRF data (Table 1) indicates Al and oxygen contents are $85.23 \%$ and $13.58 \%$ respectively. Graedel (1989) reported that enhanced corrosion occurs in marine environments. Wilkinson and Patterson (1941) investigated the effect of $\mathrm{NaCl}$ particles on the corrosion of $\mathrm{Al}$ at $293 \mathrm{~K}$. The weight change due to $\mathrm{NaCl}$ particles was linear with time. Sanyal and Bhandwar (1962) also reported similar results in their investigation of the effect of $\mathrm{NaCl}$ particles on the corrosion of $\mathrm{Al}$ at $313 \mathrm{~K}$.

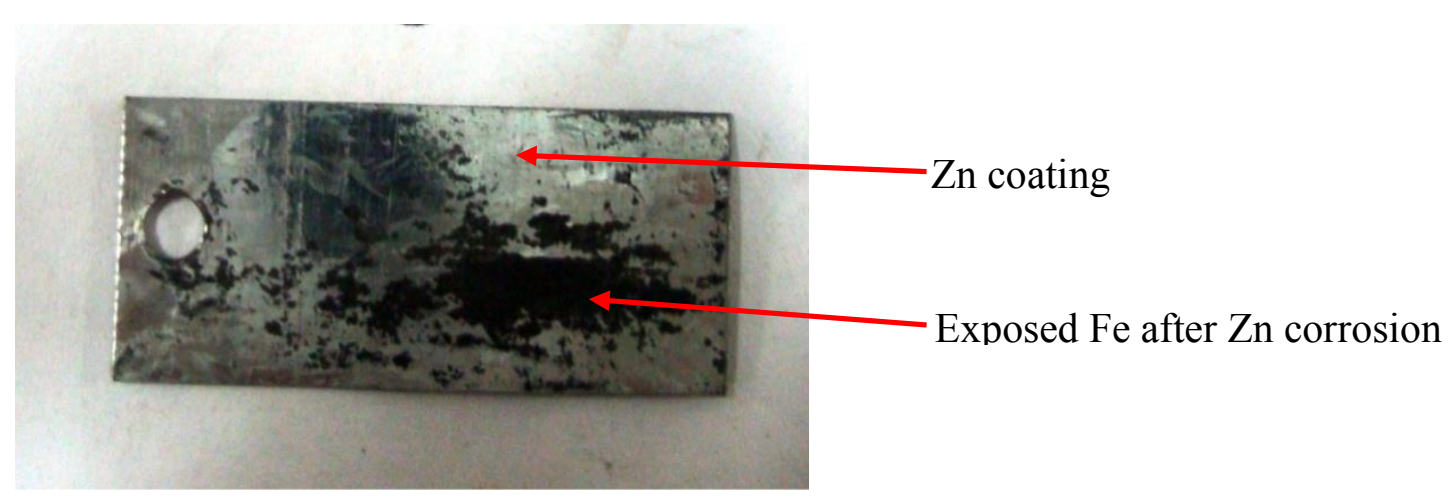

Figure 4. Photograph of galvanized steel sample after corrosion.
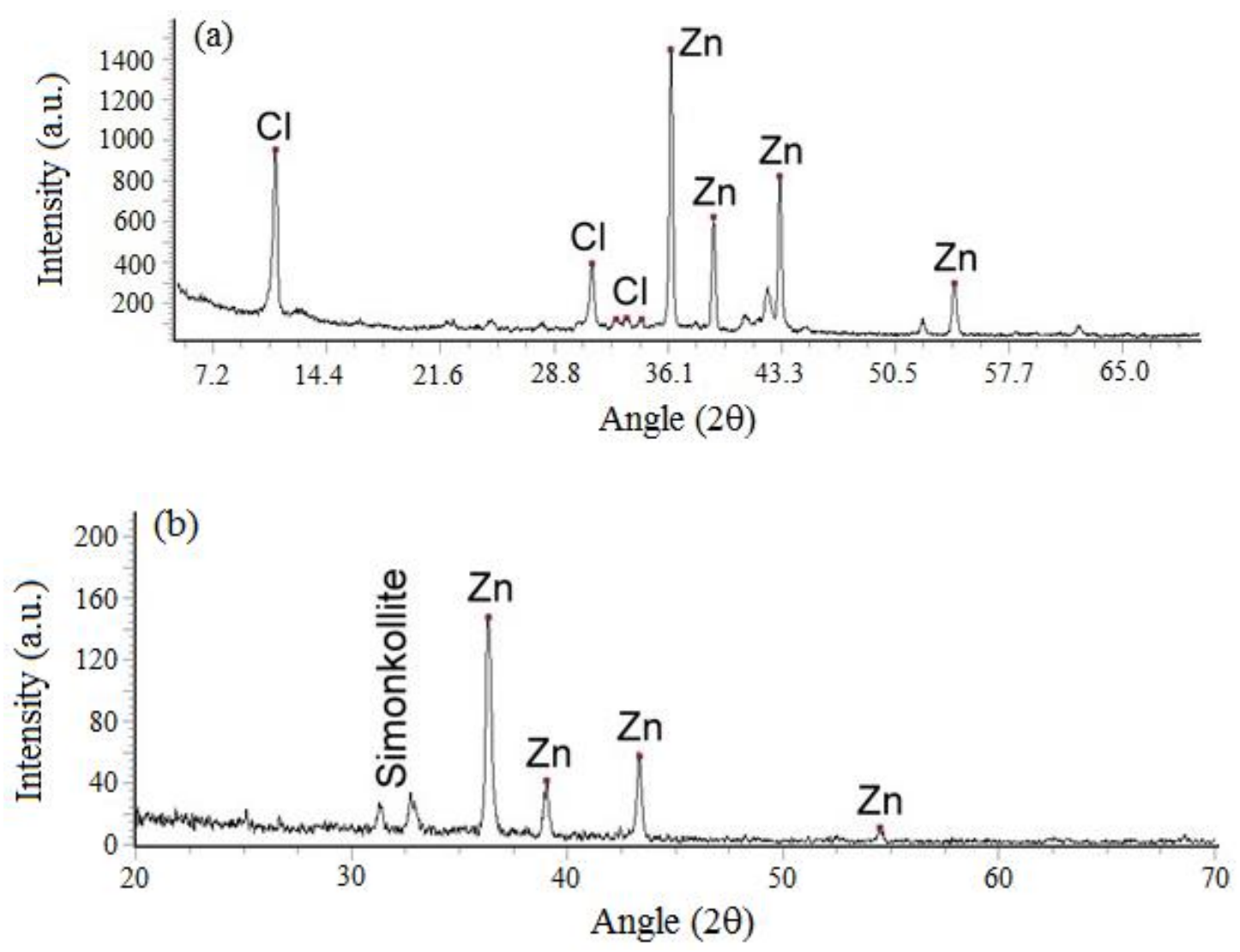

Figure 5. XRD pattern of galvanized steel after five days immersion in (a) $5 \% \mathrm{NaCl}$ solution, (b) rain water. 


\section{(c) Corrosive environment: rain water}

Rain water causes higher corrosion than sea water. Rain water falls through the atmosphere so it collects oxygen gas which increases the corrosion rate. Rain water was collected from Dhaka city. As the pollution is high in Dhaka city, the rain water is acidic in nature (Abdulkarim et al., 2009), and thus the corrosion rate is high. In the case of galvanized steel initially the amount of reactants was high but with increasing exposure time this amount decreased resulting in inhibition of the corrosion rate (Figure 3(c)). The XRD test revealed several peaks of Zn (Figure 5(b)). The XRD pattern shows deviations because of the formation of an amorphous phase on the surface. The amorphous phase is Simonkollite $\left[\mathrm{Zn}_{5}(\mathrm{OH})_{8} \mathrm{Cl}_{2} \cdot \mathrm{H}_{2} 0\right]$. The XRF test (Table 1) revealed $77.01 \% \mathrm{Zn}$ on steel substrate indicating more $\mathrm{Zn}$ corrosion than for sea water. When the $\mathrm{Zn}$ surface becomes wet with rain, an electrochemical process begins, resulting in corrosion of galvanized steel (Nriagu, 1978). A film of basic zinc carbonate, $2 \mathrm{ZnCO}_{3} 3 \mathrm{Zn}(\mathrm{OH})_{2}$, forms on galvanized steel structures in long exposures (Flinn, Cramer, Carter, Hurwitz, \& Linstrom, 1986). This film tends to inhibit further $\mathrm{Zn}$ corrosion resulting in a decrease of the corrosion rate with exposure time. However, there are environmental conditions in which film removal processes compete with film formation. In the case of $\mathrm{Al}$, the corrosion rate increases (Figure 3(c)) but the mdd values are very small. XRD shows only an Al peak and XRF indicates less Al deterioration ( $\mathrm{Al}$ is $98.8 \%$ in the corroded sample) (Table 1). It is generally agreed that deposition of $\mathrm{SO}_{2}$, and chlorides and the $\mathrm{pH}$ in rain water are major factors that determine the corrosion rate of $\mathrm{Al}$. In the presence of $\mathrm{SO}_{2}$, oxidizing agents such as $\mathrm{O}_{3}$ and $\mathrm{H}_{2} \mathrm{O}_{2}$ may also play a role in the corrosion of $\mathrm{Al}$ (Graedel, 1989). Compared to galvanized steel, Al corrodes rather slowly in rain water, because it forms an insulating amorphous oxide film of low solubility in air and aqueous solutions over the $\mathrm{pH}$ range from 4 to 8.6 (Syed, 2006). The corrosion rate in mdd for both galvanized steel and $\mathrm{Al}$ equalized after five days of exposure. The corrosion rate of galvanized steel tends to decrease whereas that of Al shows an increasing trend. This suggests that galvanized steel might be of superior corrosion resistance compared to $\mathrm{Al}$ after five days exposure in rain water.

\section{Surface Morphology of Corroded Sample}

SEM images of galvanized steel samples are shown in Figure 6. The samples were exposed for five days in corrosive environments. The SEM image of the unetched substrate sample shows an almost uniform surface (Figure 6(a)) before the corrosion test. Differences in surface elevation are visible as the sample surface is not polished. The sample in $5 \% \mathrm{NaCl}$ solution corrosion test shows some white corrosion product, or nodules, which are randomly arranged over the corroded surface, and also shows a separate layer on the surface. A sample corroded in sea water reveals a few white nodules attached to the sample surface. The sample of rain water shows a cavity, and some corrosion products or nodules (Figure 6(d)). These are small in number and randomly oriented over the surface. Thus major corrosion products appear on the sample tested in $5 \% \mathrm{NaCl}$ solution. This morphology is consistent with the corrosion measurement result found in Figure 3. SEM images of Al samples are shown in Figure 7. These samples were also exposed for five days in a corrosive environment. The SEM image of the unetched base sample shows almost uniform surface (Figure $7(\mathrm{a})$ ). 


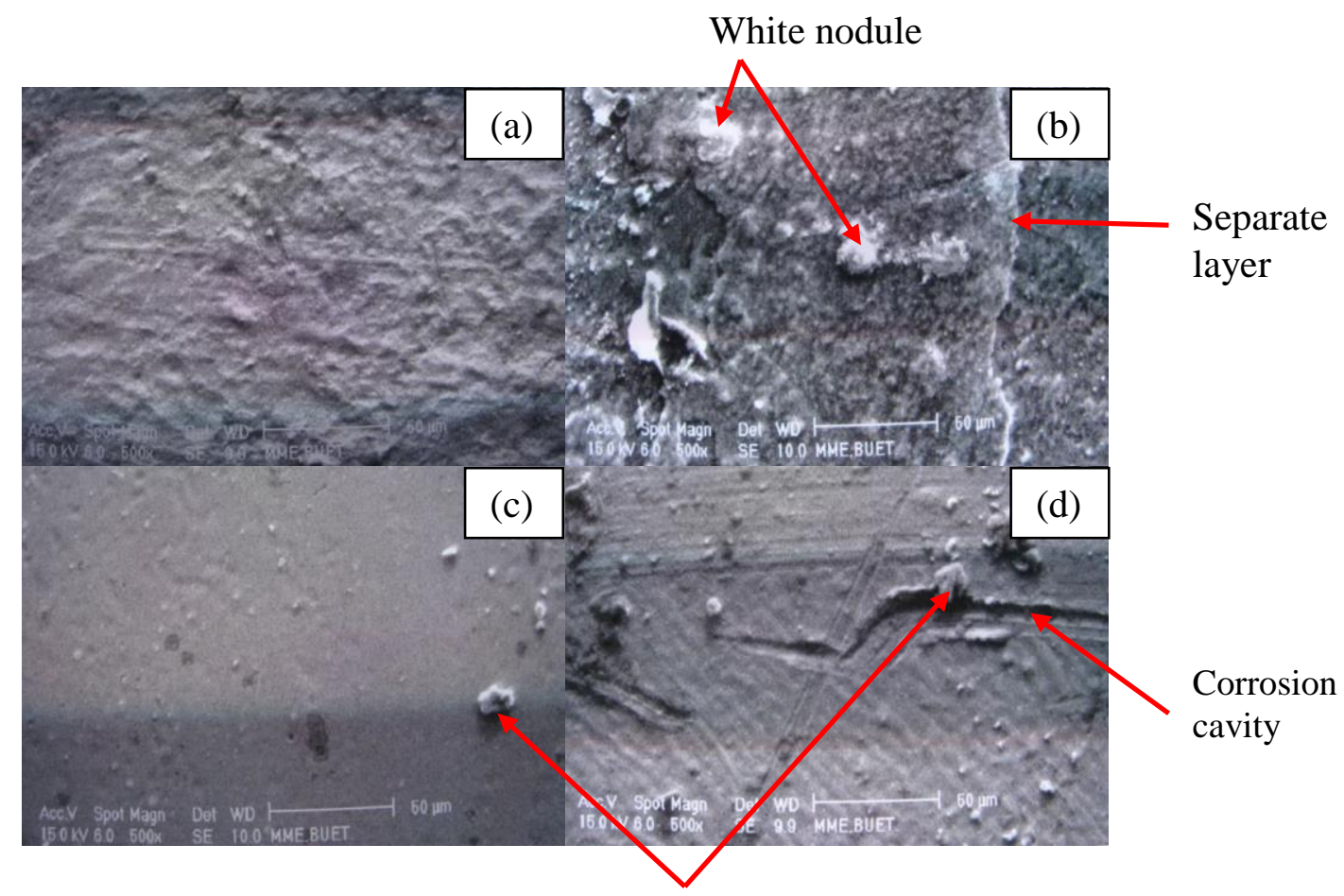

White nodule

Figure 6. SEM of galvanized steel (a) before corrosion; after corrosion in (b) $5 \% \mathrm{NaCl}$ solution; (c) sea water and (d) rain water. All corrosion tests were continued for 5 days.

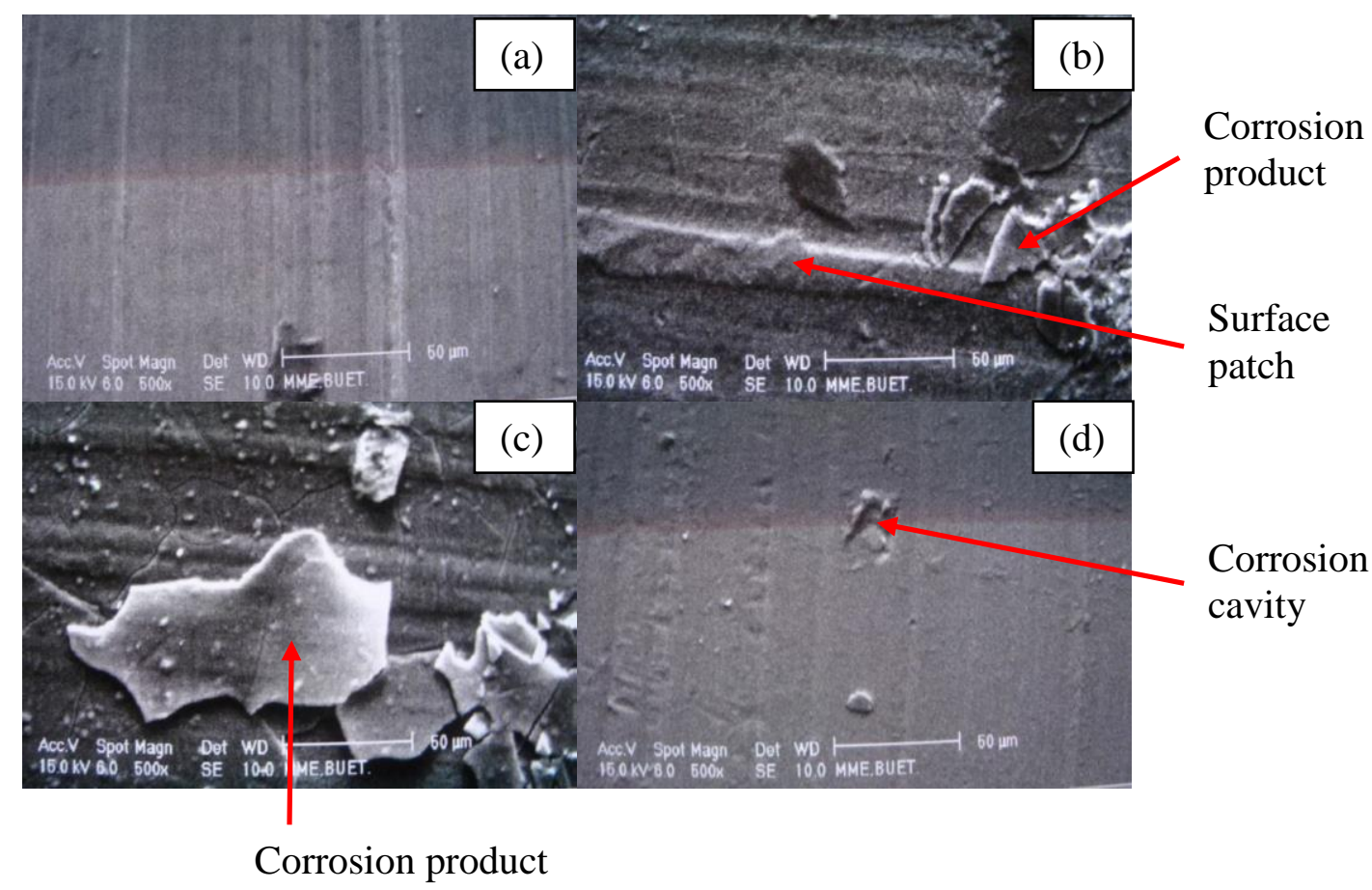

Figure 7. SEM of $\mathrm{Al}$ (a) before corrosion; after corrosion in (b) $5 \% \mathrm{NaCl}$ solution; (c) sea water and (d) rain water. All corrosion tests were continued for 5 days

The SEM image of the Al sample corroded in $5 \% \mathrm{NaCl}$ solution shows corrosion product embedding on the surface which inhibits further corrosion of the $\mathrm{Al}$ 
sample in this environment. A longitudinal surface patch is also observed along with the corrosion product (Figure 7(b)). The sample in sea water shows generation of large corrosion products which forced the layer apart sometime after the corrosion commenced (Figure 7(c)). The corrosion products might be basic aluminum sulfates and amorphous aluminum sulfate hydrate under these conditions (Barton, 1976; Graedel, 1989), because in addition to chlorides, sea water contains sulfide salts (Jayaraman, 1951). Identification of the corrosion products would be confirmed by Energy Dispersive X-ray (EDX) and XRD analyses exactly over the products. Stress developed during corrosion is believed to be responsible for corrosion product removal. Corrosion product wedging action causes the propagation of exfoliation attack (Fontana, 1967) which increases the corrosion rate as time passes, i.e. exposure time increases. A consistent corrosion rate data is seen in Figure 3(b). Corrosion in rain water produced cavities on the surface.

\section{CONCLUSIONS}

A corrosion test of galvanized steel and $\mathrm{Al}$ was conducted in $5 \% \mathrm{NaCl}$ solution, sea water and rain water. Compositional variation, corroded surface characteristics and surface morphology were studied. Based on the experimental results and analysis, the following conclusions have been drawn:

a) Varied results were obtained for both galvanized steel and Al. Corrosion rate decreases with increase of exposure time in a $5 \% \mathrm{NaCl}$ solution both for $\mathrm{Al}$ and galvanized steel. In comparison, an increasing trend in corrosion rate is observed for both the samples in sea water. The result in rain water is seen to be decreasing and increasing for galvanized steel and $\mathrm{Al}$ respectively.

b) The highest corrosion rate for galvanized steel $(25.59 \mathrm{mdd})$ is found in a $5 \% \mathrm{NaCl}$ environment whereas no corrosion occurred in sea water after one day of exposure.

c) The highest corrosion rate for $\mathrm{Al}(5.71 \mathrm{mdd})$ is found in a $5 \% \mathrm{NaCl}$ environment whereas no corrosion is seen in either sea water or rain water environments after two days and one day of exposure respectively.

d) $\mathrm{Al}$ is proved to be more corrosion resistant in all three environments under the test conditions performed in this study. For long term exposure in rain water, galvanized steel might be more corrosion resistant than $\mathrm{Al}$.

\section{REFERENCES}

Abdulkarim, B. I., Abdullahi, Y. A., \& Salam, K. A. (2009). Corrosion resistance of commercial roofing sheets to acid rain water in eleme, rivers, nigeria. International Journal of Chemical Technology Research, 1(4), 802-806.

Al-Fozan, S. A., \& Malik, A. U. (2005). Effect of seawater level on corrosion behavior of different alloys. Paper presented at the International Desalination Association (IDA) World Congress Conference, Singapore.

Bajat, J., Stanković, S., Jokić, B., \& Stevanović, S. (2010). Corrosion stability of zn-co alloys deposited from baths with high and low co content- the influence of deposition current density. Surface and Coatings Technology, 204(16), 27452753. 
Barton, K. (1976). Protection against atmospheric corrosion: Theories and methods. New York: John Wiley \& Sons.

Flinn, D., Cramer, S., Carter, J., Hurwitz, D., \& Linstrom, P. (1986). Materials degradation caused by acid rain. Paper presented at the American Chemical Society Symposium Series, Washington, D.C.

Fontana, M. G. (1967). Corrosion engineering. New York: McGraw-Hill.

Fontana, M. G. (1987). Corrosion engineering (3rd edition). New York: McGraw-Hill Book Company Inc.

Graedel, T. E. (1989). Corrosion mechanisms for aluminum exposed to the atmosphere. Journal of the Electrochemical Society, 136(4), 204-212.

Hagioglu, P., Gheorghies, C., Cantaragiu, A. M., \& Moisa, S. (2010). The accelerated corrosion behaviour in saline environments of some samples made of tombac, copper and aluminium. Journal of Science and Arts, 1(12), 153-160.

Hatch, J. E. (1984). Aluminum: Properties and physical metallurgy: ASM International. Jayaraman, R. (1951). Observations on the chemistry of the waters of the bay of bengal off madras city during 1948-1949. Paper presented at the Proceedings of the Indian Academy of Sciences-Section B.

Kartsonakis, I. A., Balaskas, A. C., Koumoulos, E. P., Charitidis, C. A., \& Kordas, G. C. (2012). Incorporation of ceramic nanocontainers into epoxy coatings for the corrosion protection of hot dip galvanized steel. Corrosion science, 57, 30-41.

Larson, T. E. (1975). Corrosion by domestic waters. Illinois state water survey (isws) 75 (Vol. 59): Department of Registration and Education.

Lin, B.-L., Lu, J.-T., \& Kong, G. (2008). Effect of molybdate post-sealing on the corrosion resistance of zinc phosphate coatings on hot-dip galvanized steel. Corrosion science, 50(4), 962-967.

Nriagu, J. O. (1978). Sulfur in the environment. Part ii. Ecological impacts. New York: John Wiley \& Sons.

Sanyal, B., \& Bhandwar, D. V. (1962). Atmospheric corrosion by electrolyte nuclei. Journal of Scientific and Industrial Research, 21, 243-248.

Sherif, E.-S. M., Almajid, A. A., Bairamov, A. K., \& Al-Zahrani, E. (2012). A comparative study on the corrosion of monel-400 in aerated and deaerated arabian gulf water and 3.5\% sodium chloride solutions. International Journal of Electrochemical Science, 7(4), 2796-2810.

Sherif, E. M., Almajid, A. A., Latif, F. H., \& Junaedi, H. (2011). Effects of graphite on the corrosion behavior of aluminum-graphite composite in sodium chloride solutions. International Journal on Electrochemical Science, 6, 1085-1099.

Syed, S. (2006). Atmospheric corrosion of materials. Emirates Journal for Engineering Research, 11(1), 1-24.

Wan Nik, W. B., Sulaiman, O., Fadhli, A., \& Rosliza, R. (2010). Corrosion behaviour of aluminum alloy in seawater. Paper presented at the The International Conference on Marine Technology.

Wilkinson, J. H., \& Patterson, W. S. (1941). The influence of humidity on the atmospheric corrosion of zinc, aluminium, and iron coated with electrolytes. Journal of the Society of Chemical Industry, 60(2), 42-44. 